\title{
Abundance and survival of a seed-infesting weevil, Pseudanthonomus hamamelidis (Coleoptera: Curculionidae), on its variable-fruiting host plant, witch-hazel (Hamamelis virginiana)
}

\author{
DIANE DE STEVEN Division of Biological Sciences, University of Michigan, \\ Ann Arbor, Michigan
}

\begin{abstract}
The relative importance of seed abundance and of mortality factors in the population biology of Pseudanthonomus hamamelidis, a hostspecific predispersal seed predator on Hamamelis virginiana, is evaluated by analysis of weevil life tables and abundance estimates in three years with markedly different magnitudes of fruit production.

2. Fruit production of marked Hamamelis individuals averaged $3.36 \mathrm{~m}^{-2}$ in 1978 , increased three- to four-fold in 1979, and declined again in 1980. More individuals fruited in 1979 than in the other two years.

3. The early larval stage of P.hamamelidis incurred the greatest mortality, with $42-58 \%$ dying from often undeterminable causes. Losses in the egg stage ranged from $22 \%$ to $31 \%$. Three parasitoid species each accounted for minor mortality. Generation survival was similar in all three years, ranging from $21 \%$ to $28 \%$.

4. The percentage of Hamamelis fruit crops infested by P.hamamelidis was high in 1978, averaging $76 \%$, but was much lower in 1979, the year of abundant fruit. In 1980, when fruit were less abundant again, infestation was nearly complete. Egg densities on fruits were lower in 1979 than in the other two years.

5. The fluctuating fruit crops of Hamamelis are responsible for limitation of P.hamamelidis numbers during poor fruiting years. The occasional highly productive fruiting year results in satiation of weevil populations and concomitant seed escape by Hamamelis. Mortality factors appear less important in influencing weevil population dynamics.
\end{abstract}

\section{Introduction}

Many temperate forest tree populations exhibit dramatic yearly fluctuations in seed production (e.g. Formosof, 1933; Christisen, 1955; Fowells, 1965), which in turn may influence the abundances of seed consumers (Lauckhart, 1957; Svardson, 1957; Smith, 1970; Mattson, 1971). Populations of relaCorrespondence: Dr Diane De Steven, Smithsonian Tropical Research Institute, APO Miami 34002, U.S.A. tively specialized insects are frequently a major source of seed loss in these trees (e.g. Graber, 1964) and, as specialists, are particularly likely to be affected by variations in seed abundance. High infestation rates in poor seed crop years (e.g. Christisen, 1955; Kraft, 1968; Gibson, 1972; Miller, 1973; Gardner, 1977) appear to limit seed insect populations, and the occasional good seed crop year 'satiates' these limited populations to result in lower infestation levels and greater successful

0307-6946/81/1100-0387\$02.00 ๑ 1981 Blackwell Scientific Publications 387 
seed production (Janzen, 1971). Predators and parasitoids appear to be less important for seed insect population dynamics compared with the effects of variable seed crops, but few studies have examined the potential of natural enemies in any detail (Kraft, 1968; Harbo \& Kraft, 1969).

While fruiting periodicity is well documented for forest trees, little is known about patterns of fruiting and fruit loss in other segments of the forest community. A common understory shrub of eastern deciduous forests in the United States, witch-hazel (Hamamelis virginiana L.), has been reported to have highly irregular annual fruit production (Wood, 1974), although quantitative data have previously been lacking. This shrub has one major seed predator, a host-specific weevil (Pseudanthonomus hamamelidis Pierce, Curculionidae). I collected life table information for $P$.hamamelidis in order to evaluate the roles of seed abundance and of natural enemies in its population biology. Here I compare the dynamics of $P$.hamamelidis in three years with markedly different magnitudes of witch-hazel fruit production to illustrate relationships among fruit abundance, weevil abundance, and consequent fruit damage. Although these data are not sufficient to identify 'key factors' (Morris, 1959) in the population dynamics of the weevil, they provide a preliminary indication of the relative importance of seed crop sizes and of mortality in influencing weevil abundances.

Adult P.hamamelidis emerge from hibernation in mid-May, when witch-hazel fruits are initiated, and lay eggs on the developing fruits from mid-June to early July. The larvae burrow into the fruits upon hatching and develop through three larval instars in consuming the fruit contents. Pupation takes place within the fruits. New adults emerge from mid-August to early September, then go into hibernation until the following spring. Further details of the biology of P.hamamelidis and its associated parasites can be found in De Steven (1980).

\section{Methods}

The study was conducted on the E. S. George Reserve, Livingston Co., Michigan, a 464 ha preserve containing a mixture of oak-hickory forest, open field, and swampland. A recent description of the area is given in McCullough (1979). As part of a larger study (De Steven, 1980), four distinct and widely separated stands of witch-hazel had been selected for intensive work. Two of these (L1 and L2) were extensive ( $>0.2 \mathrm{ha}$ ), while the other two (S1 and S2) were small stands extending over an area of only $400-500 \mathrm{~m}^{2}(0.04-0.05 \mathrm{ha})$.

The development of P.hamamelidis from egg to adult takes place entirely within the infested witch-hazel fruit; thus life table data for this period can be obtained by dissecting fruits collected periodically through the summer. Fruits occur on the plant in infructescences of one to three fruit, and these fruit clusters are a convenient unit for sampling, although the actual number of fruits per cluster and the number of these that are infested are both somewhat variable. For the purposes of this study, in each site on each sampling date, ten clusters with at least one infested fruit per cluster were collected at random from each of five plants, yielding fifty clusters with fifty to 100 infested fruits to be pooled as a single sample. More extensive sampling was undesirable due to the relatively limited size of the witch-hazel stands and the low levels of fruit production by the plants in most years.

Sampling was timed to coincide with the completion of four stages in the weevil's life history: (1) egg hatch, (2) early larval period, (3) late larval and pre-pupal periods, and (4) adult emergence. In 1978, samples were collected in mid-June, early July, the end of July and early September. The June sample was subsequently found to be inadequate for estimation purposes, and in subsequent years this sampling date was omitted and another added in mid-August to provide better information on the pre-pupal stage. In 1980 the September sample could not be obtained, but since the timing of the weevil's life cycle was earlier than in the two previous years, the other three samples proved sufficient for estimation.

All fruits in each sample were dissected under a low-power, binocular microscope, and the numbers and stages of the weevils in each were recorded along with the causes of mortality where these could be determined. Percentage mortalities for the various stages in each sample were calculated based on the 
total number of eggs laid in the sample and followed the methods of Varley et al. (1973) as applied to data for the knapweed gallfly Urophora jacaena (Hering) (Varley, 1947). This approach is particularly appropriate, since the gall and fruit are analogous feeding cells for their associated insects.

The most stable unit upon which to base the life table is the single infested witch hazel fruit. Total fruit production and the percentage of fruits infested by the weevil can be determined for a sample plot of fixed area by counting the fruits on all shrubs in that plot and recording the number of damaged and undamaged fruits (oviposition marks are easily seen on the fruit surface). Such a count is feasible for moderate-sized plots because of the relatively low level of fruit production by witch-hazel plants. The life table data can then be converted by multiplication to absolute estimates per unit area for the plot area sampled. This yields a more reliable estimate than could be calculated on a per plant basis, since fruit production varies considerably among plants within a site as a result of a multi-aged population structure. Estimates for specific stages of the life table were derived as follows:

Egg mortality. The number of eggs laid per infested fruit was counted directly and averaged for the two July samples. Percentage egg mortality is also averaged from the two July samples. The August and September samples proved inadequate for estimation because continued growth of damaged fruits sometimes obliterated evidence of unhatched eggs.

Early larval mortality. The August sample provided the earliest direct estimate, since most larvae had reached the late-larval period by then, but was not obtained in 1978. An indirect estimate was derived by subtraction from the number of live larvae in the September sample and the number of eggs hatched per fruit. This yielded the sole estimate in 1978, and was averaged with the August estimate in 1979. The August estimate was used in 1980.

Late larval mortality. All observed deaths during this period were attributable to the parasite Bracon sp. (Hymenoptera: Braconidae), the larva of which feed solitarily and externally on the third-instar weevil larva.
Estimates of braconid parasitism from the late July and September samples were averaged in 1978, from the August and September samples in 1979, and from the late July and August samples in 1980.

Pre-pupal mortality. Just as the weevil larva is preparing a pupation cell, it may be attacked by one of two chalcid parasites, Tetrastichus sp. and Entedon sp. (both Hymenoptera: Eulophidae), the larvae of which feed solitarily and internally. In 1978 a single estimate was derived from the September sample, while the August and September estimates were averaged in 1979. The August estimate was used in 1980.

Pupal mortality and adult emergence. The September sample provided a single estimate in 1978 and 1979 , and the August sample in 1980. Pupal mortality was quite low and samples were too small for site-specific estimates, so a pooled mortality rate was used over all sites in a given year. Sex ratios of emerging adults were obtained from dissection of sixty-three newlyeclosed adults collected in 1979. It was not possible to obtain absolute estimates of spring adults emerging from hibernation due to their low densities.

Life tables were constructed separately for each of the four sites, and the composite life tables for each year represent the average of these four. The format follows Harcourt (1969) where $x=$ age interval, $l x=$ number alive at the beginning of age interval $x, d x=$ number dying within $x, d x F=$ factor(s) responsible for deaths, $d x, q x=$ mortality rate within $x=(d x / L x)$, and $S x=$ survival rate within $x=(l-q x)$. Absolute estimates of weevil densities (eggs and new adults) in each site were based on $400 \mathrm{~m}^{2}(20 \times 20 \mathrm{~m})$ plots $\left(500 \mathrm{~m}^{2}\right.$ in the case of plot S2) for which total fruit production and weevil infestation rates had been recorded in the three years; total fruit abundances used here are the numbers of fruit of sufficient size for weevil oviposition, counted after early fruit abortion (De Steven, 1980). In the case of the two small stands S 1 and $S 2$, the fixed-area plots encompassed the entire area of the stand. Thus it was necessary to sample fruits directly from the plots under study in the small stands, while fruits could be collected from plants near to, but outside, the plots in the larger stands L1 and L2. 
TABLE 1. Hamamelis virginiana fruit production in four plots of fixed area.

\begin{tabular}{lllr}
\hline Year & $n$ & $\begin{array}{l}\text { Mean number } \\
\text { of plants } \\
\text { with fruit } \\
\pm \mathrm{SD}\end{array}$ & $\begin{array}{l}\text { Mean number } \\
\text { of fruit } \\
\text { per } \mathrm{m}^{2} \pm S D\end{array}$ \\
\hline 1978 & 4 & $26 \pm 5$ & $3.36 \pm 0.87$ \\
1979 & 4 & $57 \pm 7$ & $10.76 \pm 5.04$ \\
1980 & 4 & $33 \pm 9$ & $5.52 \pm 1.67$ \\
\hline
\end{tabular}

\section{Results}

\section{Fruit availability}

The number of witch-hazel fruits available to P.hamamelidis varied markedly over the period 1978-80 (Table 1). In the study plots about twice as many plants fruited in 1979 than in either 1978 or 1980 . In addition, total fruit abundance increased three-fold from 1978 to 1979; the high variance in 1979 is partly due to one plot (S2) that did not increase its fruit production as much as the other three plots (cf. Table 5). From 1979 to 1980 there was a two-fold decrease in fruit production. Partial data from 1977 indicated fruit abundances similar to 1978 levels, thus overall fruit production was relatively poor in three of four years.

The variation in fruit crop size is directly related to variation in flower production for each year's crop, but is also influenced by pollination success (De Steven, in prep.). For example, the larger fruit crops of 1979 were the result of both a much higher flower production and also a higher percentage fruit set than for the 1978 crops. The 1980 fruit crops came from the lowest flower production in three years, but from the highest percentage fruit set, so that the decrease from 1979 to 1980 was not as great as expected. Specific factors controlling annual variations in flower production and pollination success are not known in this species.

\section{Weevil survivorship}

Composite life tables for the 1978-80 generations of P.hamamelidis, based on the mean number of eggs laid per attacked witchhazel fruit, are presented in Table 2. Although in most instances eggs occur singly on attacked fruits, a variable proportion of the fruits examined had two or more eggs (Table 3). Analysis of variance showed significant variation in the mean number of eggs per fruit among the three years $(F=12.03$; $d f=2,9 ; P<0.01$ ), due to the much lower mean in 1979 , the year of abundant fruit. The maximum number of eggs per fruit was also lower in 1979 than in the other two years (Table 3).

The percentage of eggs failing to hatch ranged from $22 \%$ to $31 \%$, making this the second highest source of mortality after early larval mortality (Table 2). The proportion of total egg mortality attributable to specific causes could not be estimated with the material available, and in some cases the precise cause of death could not be determined. Occasionally, only empty egg shells were found, as if the contents had been eaten or sucked away, but no predators were observed actually feeding on eggs, nor were egg parasites found in the fruit samples examined.

The exact causes of early larval mortality were also uncertain, although this stage incurred the highest mortality, exceeding $40 \%$ (Table 2). Many of these dead larvae were covered with fungal hyphae, but fungal attack may have been secondary following death from some other factor. Some may have starved in attempting to burrow into the fruit centre, if the fruit pericarp is less suitable nutritionally than the seeds. In multiplyinfested fruits in which more than one ege hatched, larger larvae probably cannibalized smaller larvae, since a single fruit can only support the complete development of one weevil in most cases. All late larval and prepupal mortality was attributable to parasites, first the braconid wasp Bracon sp., and subsequently the chalcids Tetrastichus sp. and Entedon sp. Over the three-year period, parasitism by the braconid appeared to decrease in severity, while chalcid parasitism increased. Attack by the two chalcids occurs contemporaneously, so the effects of the two species could not be examined separately.

Pupal mortality was very low and probably due to failures in development and emergence in most instances (Table 2). Occasionally, pupae were preyed upon by the larvae of a clerid beetle that gained access to fruits that had split open as a result of weevil feeding damage. New weevil adults hibernate during 
TABLE 2. Life tables for the 1978-80 generations of Pseudanthonomus hamamelidis.

\begin{tabular}{|c|c|c|c|c|c|}
\hline$x$ & $b x$ & $d x F$ & $d x$ & $100 q x$ & $100 S x$ \\
\hline \multicolumn{6}{|l|}{1978} \\
\hline$E_{\text {g8 }}$ & 1.26 & $\begin{array}{l}\text { Infertility, fungus, developmental } \\
\text { failure }\end{array}$ & 0.28 & 22 & 78 \\
\hline Early larval & 0.98 & Fungus, cannibalism, unknown & 0.57 & 58 & 42 \\
\hline Larval, third instar & 0.41 & Bracon sp. & 0.11 & 27 & 73 \\
\hline Pre-pupal & 0.30 & $\begin{array}{l}\text { Chalcids (Entedon sp., } \\
\text { Tetrastichus sp.) }\end{array}$ & 0.03 & 11 & 89 \\
\hline Pupal & 0.27 & Predation, developmental failure & 0.01 & 2 & 98 \\
\hline Adult & 0.26 & & & & \\
\hline Generation & & & 1.00 & 79 & 21 \\
\hline \multicolumn{6}{|l|}{1979} \\
\hline Egg & 1.08 & $\begin{array}{l}\text { Infertility, fungus, developmental } \\
\text { failure }\end{array}$ & 0.28 & 26 & 74 \\
\hline Early larval & 0.80 & Fungus, cannibalism, un known & 0.46 & 58 & 42 \\
\hline Larval, third instar & 0.34 & Bracon sp. & 0.02 & 7 & 93 \\
\hline Pre-pupal & 0.32 & $\begin{array}{l}\text { Chalcids (Entedon sp., } \\
\text { Tetrastichus sp.) }\end{array}$ & 0.04 & 14 & 86 \\
\hline Pupal & 0.28 & Predation, developmental failure & 0.01 & 5 & 95 \\
\hline Adult & 0.27 & & & & \\
\hline Generation & & & 0.81 & 76 & 24 \\
\hline \multicolumn{6}{|l|}{1980} \\
\hline Egg & 1.27 & $\begin{array}{l}\text { Infertility, fungus, developmental } \\
\text { failure }\end{array}$ & 0.39 & 31 & 69 \\
\hline Early larval & 0.88 & Fungus, cannibalism, unknown & 0.37 & 42 & 58 \\
\hline Larval, third instar & 0.51 & Bracon sp. & 0.02 & 4 & 96 \\
\hline Pre-pupal & 0.49 & $\begin{array}{l}\text { Chalcids (Entedon sp., } \\
\text { Tetrastichus sp.) }\end{array}$ & 0.11 & 22 & 78 \\
\hline Pupal & 0.38 & Predation, developmental failure & 0.03 & 7 & 93 \\
\hline Adult & 0.35 & & & & \\
\hline Generation & & & 0.92 & 72 & 28 \\
\hline
\end{tabular}

$L x$ and $d x$ are numbers alive and dying, respectively, per infested Hamamelis fruit.

the winter and re-emerge in the spring to mate and oviposit; adult dispersal and overwintering mortality could not be assessed in the present study.

The survival of the three egg cohorts through the immature stages is summarized in Fig. 1. Generation survival equations (Harcourt, 1969) for each site indicate the interplot variation in survival upon which the composite life tables were based and also provide a compact comparison of stage-specific survival rates (Table 4 ). The low survival of early larvae $\left(S_{\mathrm{el}}\right)$ in comparison with other stages is apparent (Table 4 and Fig. 1); both this stage and the egg stage are critical age intervals (not the 'key factors' of Morris (1959)) most responsible for within-generation changes in numbers. Braconid parasitism on late-stage larvae was low in all years; the lower $S_{11}$ value in 1978 was due to two
TABLE 3. Distribution of Pseudanthonomus hamamelidis eggs on Hamamelis virginiana fruits from 1978 to 1980 .

\begin{tabular}{lccc}
\hline $\begin{array}{l}\text { No. eggs } \\
\text { per } \\
\text { attacked } \\
\text { fruit }\end{array}$ & \multicolumn{2}{l}{ No. of fruit (\%) } \\
\cline { 2 - 4 } & 1978 & 1979 & 1980 \\
\hline 1 & $425(76)$ & $418(93)$ & $437(77)$ \\
2 & $120(22)$ & $32(7)$ & $110(19)$ \\
3 & $12(2)$ & $1(0.2)$ & $19(3)$ \\
4 & $2(0.4)$ & - & $3(0.5)$ \\
\hline
\end{tabular}

plots with much lower survival than the other two. Parasitism by the two chalcid species appeared to increase over the three-year period. Overall, generation survival did not differ significantly among the three years of the study. 


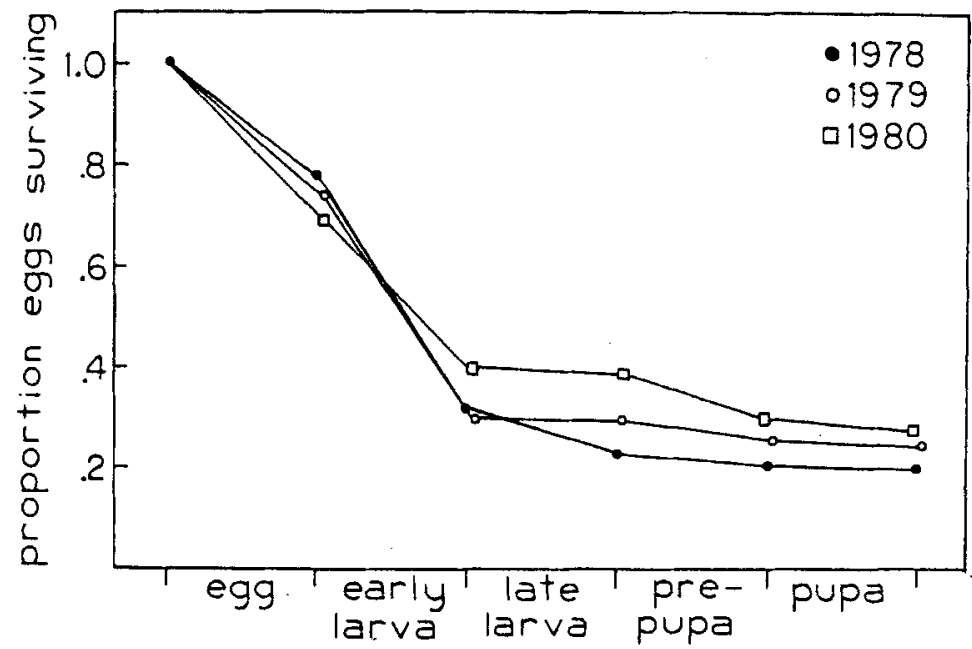

FIG. 1. Survival of three generations of Pseudanthonomus hamamelidis through immature stages from egg to new adult. Starting with an initial proportion of 1.0 eggs laid, points are the mean proportion surviving at each stage interval, averaged over four sites.

TABLE 4. Components of generation survival of the 1978-80 generations of Pseudanthonomus hamamelidis, by site.

\begin{tabular}{|c|c|c|c|c|c|c|c|}
\hline Site & GS* & $=$ & $s_{\mathrm{e}}$ & $s_{\mathrm{el}}$ & $S_{11}$ & $s_{p p}$ & $s_{p^{\dagger}}^{\dagger}$ \\
\hline \multicolumn{8}{|l|}{1978} \\
\hline L1 & 0.24 & $=$ & 0.82 & 0.38 & 0.86 & 0.93 & 0.98 \\
\hline L2 & 0.14 & $=$ & 0.78 & 0.35 & 0.60 & 0.86 & 0.98 \\
\hline S1 & 0.27 & $=$ & 0.61 & 0.64 & 0.90 & 0.79 & 0.98 \\
\hline S2 & 0.16 & $=$ & 0.90 & 0.32 & 0.58 & 1.00 & 0.98 \\
\hline \multicolumn{8}{|l|}{1979} \\
\hline L1 & 0.19 & $=$ & 0.74 & 0.32 & 0.96 & 0.98 & 0.95 \\
\hline $\mathrm{L}_{2}$ & 0.23 & $=$ & 0.74 & 0.42 & 0.90 & 0.85 & 0.95 \\
\hline S1 & 0.19 & $=$ & 0.66 & 0.42 & 0.87 & 0.81 & 0.95 \\
\hline S2 & 0.34 & $=$ & 0.81 & 0.51 & 0.98 & 0.88 & 0.95 \\
\hline \multicolumn{8}{|l|}{1980} \\
\hline L1 & 0.23 & $=$ & 0.73 & 0.48 & 0.94 & 0.76 & 0.93 \\
\hline L2 & 0.32 & $=$ & 0.60 & 0.68 & 0.99 & 0.85 & 0.93 \\
\hline S1 & 0.28 & $=$ & 0.69 & 0.62 & 0.94 & 0.76 & 0.93 \\
\hline S2 & 0.27 & $=$ & 0.75 & 0.56 & 0.96 & 0.73 & 0.93 \\
\hline
\end{tabular}

* Generation survival (GS) $=S_{\mathrm{e}} S_{\mathrm{el}} S_{11} S_{\mathrm{pp}} S_{\mathrm{p}}$, where $S_{\mathrm{e}}=$ egg survival, $S_{\mathrm{el}}=$ early larval survival, $S_{11}=$ third-instar larval survival, $S_{\mathrm{pp}}=$ pre-pupal survival, and $S_{\mathrm{p}}=$ pupal survival.

$\dagger$ Pupal survival assumed constant for all sites in a given year.

\section{Fruit abundance and weevil dynamics}

The relationship between fruit abundance and weevil numbers is summarized in Table 5 . Total egg density is estimated by multiplying the number of infested fruits by the mean number of eggs per infested fruit. Density of emerging adults is obtained from generation survival estimates for each site. The sex ratio of emerging aduits is approximately 50:50 (De Steven, 1980).

As previously noted, witch-hazel fruits were considerably more abundant in 1979 than in 1978; however, while the increases were substantial (three to four-fold) in three of the sites, the increase was less than twofold in site S2, which had the lowest fruit abundance of all sites in 1978 (Table 5). In- 
TABLE 5. Absolute estimates of Pseudanthonomus hamamelidis abundances for plots of fixed area, by site.

\begin{tabular}{|c|c|c|c|c|c|c|c|}
\hline Site & $\begin{array}{l}\text { Fruits/ } \\
\mathrm{m}^{2}\end{array}$ & $\begin{array}{l}\% \\
\text { infested }\end{array}$ & $\begin{array}{l}\text { No. } \\
\text { infested } \\
\text { fruits } / \mathrm{m}^{2}\end{array}$ & $\begin{array}{l}\text { No. } \\
\text { eggs/ } \\
\text { fruit }\end{array}$ & $\begin{array}{l}\text { Total } \\
\text { eggs } / \mathrm{m}^{2}\end{array}$ & $\begin{array}{l}\text { Generation } \\
\text { survival }\end{array}$ & $\begin{array}{l}\text { Total } \\
\text { adults } \\
\text { emerged } / \mathrm{m}^{2}\end{array}$ \\
\hline \multicolumn{8}{|l|}{1978} \\
\hline L1 & 3.89 & 96 & 3.73 & 1.26 & 4.70 & 0.24 & 1.13 \\
\hline L2 & 3.89 & 83 & 3.23 & 1.27 & 4.10 & 0.14 & 0.57 \\
\hline S1 & 3.58 & 60 & 2.15 & 1.24 & 2.66 & 0.27 & $0.72(0.54)^{*}$ \\
\hline S2 & 2.08 & 65 & 1.35 & 1.28 & 1.73 & 0.16 & $0.28(0.25)^{*}$ \\
\hline \multicolumn{8}{|l|}{1979} \\
\hline L1 & 15.03 & 45 & 6.76 & 1.05 & 7.10 & 0.19 & 1.35 \\
\hline L2 & 10.24 & 45 & 4.61 & 1.04 & 4.79 & 0.23 & 1.10 \\
\hline S1 & 13.92 & 25 & 3.48 & 1.03 & 3.58 & 0.19 & $0.68(0.58)^{*}$ \\
\hline S2 & .3 .85 & 70 & 2.70 & 1.20 & 3.24 & 0.34 & $1.10(0.94)^{*}$ \\
\hline 1980 & & & & & & . & \\
\hline L1 & 4.71 & 99 & 4.66 & 1.37 & 6.38 & 0.23 & 1.47 \\
\hline L2 & 8.01 & 88 & 7.05 & 1.22 & 8.60 & 0.32 & 2.75 \\
\hline S1 & 4.51 & 92 & 4.15 & 1.24 & 5.15 & 0.28 & $1.44(1.30)^{*}$ \\
\hline S2 & 4.85 & 91 & 4.41 & 1.24 & 5.47 & 0.27 & $1.48(1.39)^{*}$ \\
\hline
\end{tabular}

- Numbers in parentheses are live adults remaining at the site after effects of removal sampling are discounted.

festation by $P$.hamamelidis was generally high in 1978 , as it had been in 1977 , another year of low fruit availability. However, in 1979 infestation rates were considerably lower in all the sites except S2, the site with the lowest relative increase in fruit production. The same pattern is found in egg densities on infested fruits; while the mean number of eggs per fruit was significantly lower overall in 1979, this was true for all the sites individually except S2, where egg densities were comparable in 1978 and 1979 (Table 5). In 1980 fruit production decreased in three of the four sites, while increasing slightly in site S2. Weevil infestation in that year was extremely high in all sites, and egg densities were comparable to the higher 1978 ievels.

From 1978 to 1979 the population trend index, $I$ (total eggs in year $n+1 /$ total eggs in year $n$ ) (Harcourt, 1969) averaged 1.48 (range 1.17-1.87), thus weevil populations increased in 1979 in the presence of abundant fruit. From 1979 to 1980 the trend index averaged 1.46 (range $0.90-1.69$ ). Population increase was possible in 1980 even though fruit production was lower than in 1979 , because more fruit were still available in 1980 than had been infested in 1979. The only exception was site L1, where in 1980 the number of fruits available for weevil oviposition was less than the number of fruits that had been infested in the previous year. This site showed the highest egg densities and the only population decrease $(I=0.90)$ in 1980 . The nearly complete infestation of all fruits in 1980 indicates the limitation of weevil numbers by available fruit in all sites.

Potential female fecundity may range from sixty to 120 eggs per year (De Steven, 1980). However, because overwintering adult mortality could not be assessed, it was not possible to relate the egg production in a given year to the number of females emerging in the spring and to their realized fecundity, which is probabiy lower. Ratios between the total egg density in one year and the number of fallemerging adult females in the previous year were similar (range 5-9) in all cases except plot S2 in 1979. This latter plot had the highest trend index $(1.87)$ in that year despite the fact that it produced the fewest number of females of all sites in 1978 .

Since it was necessary to sample weevil populations directly from the fixed-area plots in the small stands S1 and S2 (cf. Methods), some potential females were probably removed permanently from those populations by the sampling process (Table 5 ). This was not the case in sites $\mathrm{L} 1$ and L2, which were larger and could sustain a limited amount of 
removal sampling. In site $S 1$ in 1978 this removal may have resulted in the very low infestation in 1979, assuming that dispersal of adults from other stands into $\mathrm{S} 1 \mathrm{w}$ as minimal. However, the trend index for site $S 2$ in the same year was high despite the removal of some females from the population, and infestation in 1979 was comparable to that in 1978. Nor did the removals in 1979 prevent complete infestation of available fruit in 1980. This could suggest that dispersal of adults into these stands from other areas is occurring.

\section{Discussion}

The annually variable fruit crops of witchhazel appear responsible for a pattern of fruit damage and weevil population fluctuation that is probably representative of the dynamics of interactions between specialized insect seed predators and host plants with fluctuating fruit production (Mattson, 1971; Janzen, 1971). P.hamamelidis utilized a large proportion of the available witch-hazel fruit in the poor fruiting years $1977-78$, reflected in the high attack rates and high frequencies of multiple ovipositions on single fruits. Following several years of poor fruit crops, the weevils are apparently unable to utilize all available fruit in a productive fruiting year. The three-fold increase in fruit crop sizes in 1979 was sufficient to result in lower attack rates and lower frequencies of multiplyinfested fruits, even though the weevil populations increased in the presence of abundant fruit in that year. In the one plot (S2) that did not have substantially higher fruit crops in 1979, attack rates and egg densities were more similar to those in 1978 , the poor fruiting year. In 1980, although fruit production declined again, crops were larger than in 1978 and were of sufficient size to allow further weevil population increases in all sites but one (L1). However, these increases resulted in very high attack rates on the smaller (relative to 1979) fruit crops, which effectively set the upper limit on weevil egg production in 1980. In site $\mathrm{Ll}$, where fewer fruit were available for oviposition than had been utilized in 1979 , weevil numbers actually decreased in 1980 .

Thus years of low fruit production limit weevil population size; fruits may be limiting even though $100 \%$ infestation is not achieved because some small plants with very few fruit have very low probabilities of location by searching adult weevils and because spatiallyisolated plants may be located less frequently than plants in dense stands (De Steven, 1980). The actual causes of the fluctuations in witchhazel fruit crop size are not known. They may be controlled in part by climatic variables that affect the extent of flower primordia initiation, but may also result from a reduction of photosynthetic allocation to floral initiation due to the heavy energetic demands of a large current-year seed crop (Wenger, 1957; Matthews, 1963; Kozlowski \& Keller, 1966; Shoulders, 1968; Mattson, 1978). The conflict between vegetative and reproductive energetic demands may generate a cyclical pattern in seed crop fluctuations such that highly productive years seldom occur sequentially. Thus seed predator populations are strongly resource-limited in some years, and plants in turn 'satiate' seed predators in the occasional productive years (Janzen, 1971). The inability of $P$.hamamelidis to respond immediately to sudden increases in annual fruit production is probably also a consequence of two other factors in addition to the general limitation of population size by low fruit crops: adult overwintering mortality, which reduces the number of ovipositing females, and the univoltine life history, which delays the predator 'numerical response' (Holling, 1959) to increased fruit availability until the next generation or year.

Mortality factors appear to be less important in affecting weevil population fluctuations, although more data would be needed to show this conclusively. Generation survival was similar in all years despite the varying fruit abundances and weevil densities. The GS of c. $20 \%$ is higher than the $8-12 \%$ reported for a few other seed beetles, both Bruchidae and Curculionidae (Dickason, 1960; Parnell, 1966; Mitchell, 1977) and is not sufficient to prevent weevil population increases if fruit are available, unless overwintering mortality is quite severe. Rates of braconid parasitism showed no consistent trends with varying weevil densities; in contrast, combined parasitism by the chalcid species increased with the annual increase in weevil densities. However, any density dependence in chalcid para- 
sitism may be a minor effect on population dynamics in comparison with the strong effects of fluctuating food abundance. Possibly parasitoids could play a role in depressing weevil populations during a series of years in which fruit production was relatively invariant (e.g. a series of poor fruiting years), since this would temporarily stabilize weevil numbers and provide a relatively constant resource base for an increasing parasitoid population.

\section{Acknowledgments}

This study was supported by funds from a George Reserve Scholarship, a Sigma Xi Grant-in-Aid, and several awards from the University of Michigan, including a Rackham Block Grant, Rackham Dissertation Grant, and Rackham Predoctoral Fellowship. The following scientists from the Systematic Entomology Laboratory provided insect identifications: E. E. Grissell (Chalcidoidea), P. M. Marsh (Braconidae) and D. R. Whitehead (Curculionidae). F. Evans, B. Rathcke, D. Rabinowitz, J. Vandermeer and J. Witter made helpful comments on various drafts of the manuscript. This work was submitted as part of a Ph.D. dissertation at the University of Michigan.

\section{References}

Christisen, D.M. (1955) Yield of seed by oak in the Missouri Ozarks. Journal of Forestry, 53, 439441.

De Steven, D. (1980) Insect seed predation and the reproductive ecology of witch-hazel (Hamamelis virginiana). Ph.D. thesis, University of Michigan.

Dickason, E.A. (1960) Mortality factors for the vetch bruchid, Bruchus brachialis. Journal of Economic Entomology, 53, 555-558.

Formosof, A.N. (1933) The crop of cedar nuts, invasions into Europe of the Siberian nutcracker (Nucifraga caryoctactes macrorhynchus Brehm) and fluctuations in numbers of the squirrel (Sciurus vulgaris L.). Journal of Animal Ecology, 2, 70-81.

Fowells, H.A. (1965) Silvics of forest trees of the United States. USDA Forest Service Handbook No. 271.

Gardner, G. (1977) The reproductive capacity of Fraxinus excelsior on the Derbyshire limestone. Journal of Ecology, 65, 107-118.

Gibson, L.P. (1972) Insects that damage white oak acorns. USDA Forest Service Research Paper NE-2 20.

Graber, R.E. (1964) Impact of the white pine cone beetle on a pine seedcrop. Journal of Forestry, $62,499-500$.

Harbo, J.R. \& Kraft, K.J. (1969) A study of Phaner. otoma toreuta, a parasite of the pine cone moth Laspeyresia toreuta. Annals of the Entomological Society of America, 62, 214-220.

Harcourt, D.G. (1969) The development and use of life tables in the study of natural insect populations. Annual Review of Entomology, 14, 175196.

Holling, C.S. (1959) The components of predation as revealed by a study of small-mammal predation of the European pine sawfly. Canadian Entomologist, 91, 293-320.

Janzen, D.H. (1971) Seed predation by animals. Annual Review of Ecology and Systematics, 2, $465-492$.

Kozlowski, T.T. \& Keller, T. (1966) Food relations of woody plants. Botanical Review, 32, 293-382.

Kraft, K.J. (1968) Ecology of the cone moth Las. peyresia toreuta in Pinus banksiana stands. Annals of the Entomological Society of America, $61,1462-1465$.

Lauckhart, J.B. (1957) Animal cycles and food. Journal of Wildlife Management, 21, 230-234.

Matthews, J.D. (1963) Factors affecting the production of seed by forest trees. Forestry Abstracts, 24, i-xiii.

Mattson, W.J. (1971) Relationship between cone crop size and cone damage by insects in red pine seed-production areas. Canadian Entomologist, $103,617-621$.

Mattson, W.J. (1978) The role of insects in the dynamics of cone production of red pine. Oecologia, 33, 327-349.

McCullough, D.R. (1979) The George Reserve Deer Herd: Population Ecology of a K-selected Species. University of Michigan Press, Ann Arbor.

Miller, W.E. (1973) Insects as related to wood and nut production. In: Black walnut as a crop. USDA Forest Service General Technical Report, NC.4, 91-96.

Mitchell, R. (1977) Bruchid beetles and seed packaging by Palo Verde. Ecology, 58, 644-651.

Morris, R.F. (1959) Single-factor analysis in population dynamics. Ecology, 40, 580-588.

Parnell, J.R. (1966) Observations on the population fluctuations and life histories of the beetles Bruchidius ater (Bruchidae) and Apion fuscirostre Curculionidae) on broom (Sarothamus scoparius). Journal of Animal Ecology, 35, 157-188.

Shoulders, E. (1968) Fertilization increases longleaf and slash pine flower and cone crops in Lousiana. Journal of Forestry, 66, 193-197.

Smith, C.C. (1970) The coevolution of pine squirrels (Tamiasciurus) and conifers. Ecological Monographs, 40, 349-371.

Svardson, G. (1957) The 'invasion' type of bird migration. British Birds, 50, 314-343.

Varley, G.C. (1947) The natural control of population balance in the knapweed gall-fly (Urophore jacaena). Joumal of Animal Ecology, 16, 139-187. 
Varley, G.C., Gradwell, G.R. \& Hassell, M.P. (1973) Insect Population Ecology: an Analytical Approach. Blackwell Scientific Publications, Oxford.

Wenger, K.F. (1957) Annual variation in the seed crops of loblolly pine. Journal of Forestry, 55, 567-569.
Wood, G.E. (1974) Witch-hazel. In J. D. Gill and W. M. Healy (eds.) Shrubs and vines for northeastern wildife. USDA Forest Service General Technical Report, NE-9.

Accepted 12 January 1981 